\title{
Estimación de la contaminación del aire por PM10 en Quito a través de índices ambientales con imágenes LANDSAT ETM+
}

\author{
César Iván Álvarez Mendoza* \\ Oswaldo Padilla Almeida**
}

Recibido el 18 de diciembre de 2015; aceptado el 4 de septiembre de 2016

\begin{abstract}
Air pollution in cities is a process growing every day. Currently we have sought to reduce this pollution and the factors involved through good environmental management by identifying the sources of pollution and passive techniques such as automatic air quality monitoring as the case of the city of Quito stations.

This paper conducts an investigation to define whether models generated from satellite images with field data, models adapted to simple and multiple regression, can be employed in Ecuador, with satisfactory results in Quito taking the model that best fits that has relationship between Aerosol Optical Tickness (AOT) and Particular Matter less than 10 microns (PM10) (Othman et al., 2010), with correlation values above $90 \%$.

In the city, you have data from air pollutants such as less than 10 microns (PM10) daily basis particulate matter due to the data of the monitoring stations. When combined with data processed satellite images can help to identify sites where you have problems and suggest that other cities do not have the resources to acquire and maintain permanent air stations can opt for this methodology.

The results achieved in the research for each of the 3 years itself infer the value of PM10 throughout the city.

Palabras clave: Quito, Landsat ETM+, PM10, Air Pollution.
\end{abstract}

* Carrera de Ingeniería Ambiental, Centro de Investigación en Modelamiento Ambiental, Universidad Politécnica Salesiana, Ecuador, correo electrónico: cesarivanalvarezmendoza@gmail.com

** Maestría en Sistemas de Gestión Ambiental, Departamento de Ciencias de La Tierra, Universidad de Las Fuerzas Armadas ESPE, Ecuador. 


\section{Resumo}

A contaminação do ar nas cidades é um processo que tem crescido com o passar dos anos. Atualmente se tem buscado reduzir esta contaminação e entender os fatores que a envolvem mediante uma boa gestão ambiental, identificando os focos de contaminação com técnicas como estações passivas e automáticas de monitoramento de qualidade do ar como é o caso da cidade de Quito e muitas outras cidades grandes.

O presente trabalho realiza uma pesquisa em definir se índices ambientais gerados a partir de imagens de satélite junto a dados de campo que são adaptados a modelos de regressão simples e múltiplos podem ser ocupados no Equador, obtendo-se assim resultados satisfatórios na cidade de Quito levando que o modelo que melhor se ajusta é o que relaciona linearmente a espessura ótica de aerosois (AOT) com Material Particulado maior a 10 micras (PM10) (Othman et al., 2010), com valores de correlação positiva sobre $90 \%$.

$\mathrm{Na}$ cidade se tem dados de qualidade do ar como é o caso PM10 de maneira diária graças a presença de estações de monitoramento, que ao ser combinadas com dados de imagens de satélites buscam generalizar em toda a zona de estudo os lugares de onde se tem problemas de polução atmosférica, considerando tomar ações municipais sobre estes pontos presentes.

Os resultados obtidos na pesquisa obtém para cada um dos 3 anos inferir se valor de PM10 ao longo da cidade.

Palavras chave: Quito, Landsat ETM+, PM10, Contaminação do ar

\section{Resumen}

La contaminación del aire en las ciudades es un proceso que ha crecido con el pasar de los años. Actualmente se ha buscado reducir esta contaminación y entender los factores que la involucran mediante una buena gestión ambiental, identificando los focos de contaminación con técnicas como estaciones pasivas y automáticas de monitoreo de calidad de aire como es en el caso de la ciudad de Quito y muchas otras ciudades grandes.

El presente trabajo realiza una investigación en definir si índices ambientales generados a partir de imágenes satelitales junto a los datos de campo que son adaptados a modelos de regresión simple y múltiple, pueden ser ocupados en Ecuador, obteniéndose así resultados satisfactorios en la ciudad de Quito llevando a que el modelo que mejor se ajusta es el que relaciona linealmente el espesor óptico de aerosoles (AOT) con Material Particulado mayor a 10 micras (PM10) (Othman et al., 2010), con valores de correlación positiva sobre el $90 \%$.

En la ciudad se tienen datos de calidad de aire como es el caso PM10 de manera diaria gracias a la presencia de estaciones de monitoreo, que al ser combinadas con 
datos de imágenes satelitales buscan generalizar en toda la zona de estudio los lugares donde se tienen problemas de polución atmosférica, considerando tomar acciones municipales sobre estos puntos presentes.

Los resultados obtenidos en la investigación logran para cada uno de los tres años inferir en sí el valor de PM10 a lo largo de la ciudad.

Palabras clave: Quito, Landsat ETM+, PM10, Contaminación del aire.

\section{Introducción}

Los modelos atmosféricos en imágenes satelitales resultan de la obtención a partir de años de investigaciones y estudios. La mayoría de veces dichos modelos quedan solo propuestos sin ser una manera práctica de solventar la obtención de PM10. Es por esto que se realiza el estudio para la determinación de PM10 a partir de un modelo generado con imágenes satelitales Landsat ETM+ mediante regresión lineal múltiple en las zonas áridas de Arabia Saudita, donde los resultados son satisfactorios con valores de correlación cercanos al $90 \%$ al utilizar el modelo que relaciona linealmente AOT con PM10 (Othman et al., 2010), Así se trata de emular y comprobar este algoritmo en la ciudad de Quito, tomando en consideración la aplicación de índices ambientales ya existentes sobre las imágenes satelitales y comparándolos con datos obtenidos en campo a partir de las estaciones pasivas y semiautomáticas de monitoreo de aire de la ciudad con regresiones simples y múltiples, donde el modelo que obtenga una mejor correlación será la base para generalizar e inferir el PM10 sobre toda la ciudad. Vale la pena aclarar que se utilizaron imágenes Landsat 7 en vista de que estas tienen un tamaño de pixel adecuado para un estudio semiregional como el caso de la ciudad de Quito, así como también son fáciles de obtención y fueron con las que se realizó el estudio preliminar de los otros índices en otros casos de estudio. Adicional hay que considerar que el modelo no considera la parte de características físicas de la región de estudios

\section{Metodología \\ Área de estudio}

El área de estudio seleccionada se encuentra definida dentro del Distrito Metropolitano de Quito (DMQ), y determinada por la ubicación de las estaciones pasivas que contienen la información de PM10 para las fechas de las imágenes satelitales Landsat ETM+. Esta área tiene una superficie de $900 \mathrm{~km}^{2}$ (Figura 1).

\section{Diseño del proyecto}

El PM10 es uno de los contaminantes del aire que más afecta la ciudad de Quito, es así que se busca realizar el diseño del proyecto evaluando cuál es el modelo más adecuado en base a regresión para determinar PM10 en Quito mediante imágenes 
satelitales tratadas con su respectivo análisis digital y muestreo de datos en campo (Figura 2).En la ciudad de Quito la problemática es un promedio de PM10 en 24 horas es cercano a los $75 \mu \mathrm{g} / \mathrm{m}^{3}$, que aunque es bajo sobre la normativa ecuatoriana de $100 \mu \mathrm{g} / \mathrm{m}^{3}$, estos aún están sobre las directrices de la Organización Mundial de la Salud (OMS) de $50 \mu \mathrm{g} / \mathrm{m}^{3}$ para reducción de riesgos de enfermedades agudas y crónicas derivadas de la contaminación del aire (OMS, 2014).

\section{Selección de datos base}

Para poder realizar el estudio se seleccionaron imágenes satelitales Landsat ETM+ de los años 2005, 2008 y 2011. Fueron escogidos estos años en vista de que eran imágenes con menor cantidad de cobertura de nubes en la zona de estudio y tenían épocas de toma en meses similares. No se consideraron otros meses porque la zona de estudio tiende a llevar una nubosidad mayor al $40 \%$. Adicionalmente se obtuvo los datos de la red de monitoreo pasivo del aire del contaminante PM10 de Quito en las fechas previstas por las imágenes satelitales mediante un promedio diario que arroja el equipo (Tabla 1) con ocho estaciones. Existe un cambio entre las estaciones Guamaní y Cotocollao en el 2005 y 2008 en vista de que se aplicaron normativas para reducir la concentración.

Las estaciones semiautomáticas calculan el PM10 mediante método gravimétrico en un filtro durante un periodo de muestreo de 24 horas (Secretaría del Ambiente de Quito, 2014).

Tabla 1

Datos PM10 Monitoreo Semiautomático en el Distrito Metropolitano de Quito

\begin{tabular}{lccc}
\hline Fecha Imagen & 09 de julio de 2005 & 17 de julio de 2008 & 08 de junio de 2011 \\
\hline Estación & julio 2005 & julio 2008 & junio 2011 \\
Cotocollao & 92,03 & 32,28 & 24,81 \\
Belisario & 52,14 & 38,84 & 33,17 \\
Jipijapa & 29,42 & 25,39 & 21,32 \\
Guamaní & 94,11 & 39,97 & - \\
Los Chillos & 28,52 & 31,09 & 23,58 \\
El Camal & - & - & 37,7 \\
Tababela & - & - & 25,72 \\
\hline
\end{tabular}

Nota: Promedio mensual de PM10 en $\mu \mathrm{g} / \mathrm{m}^{3}$ de acuerdo a las fechas de adquisición de las imágenes satelitales. 


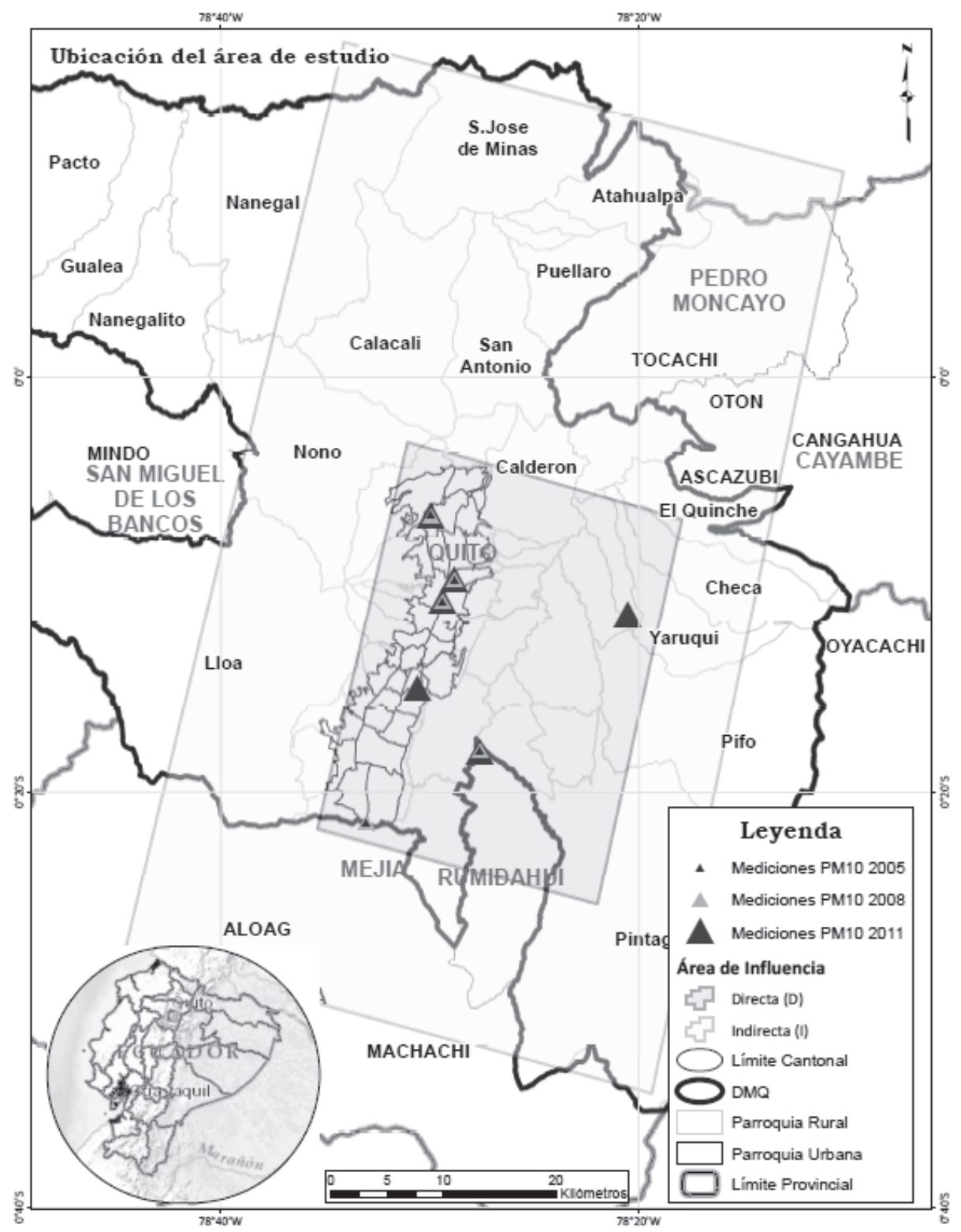

Figura 1. Ubicación de estaciones de monitoreo de calidad de aire con datos de PM10 en los años 2005, 2008 y 2011 sobre el área de estudio en el DMQ. 


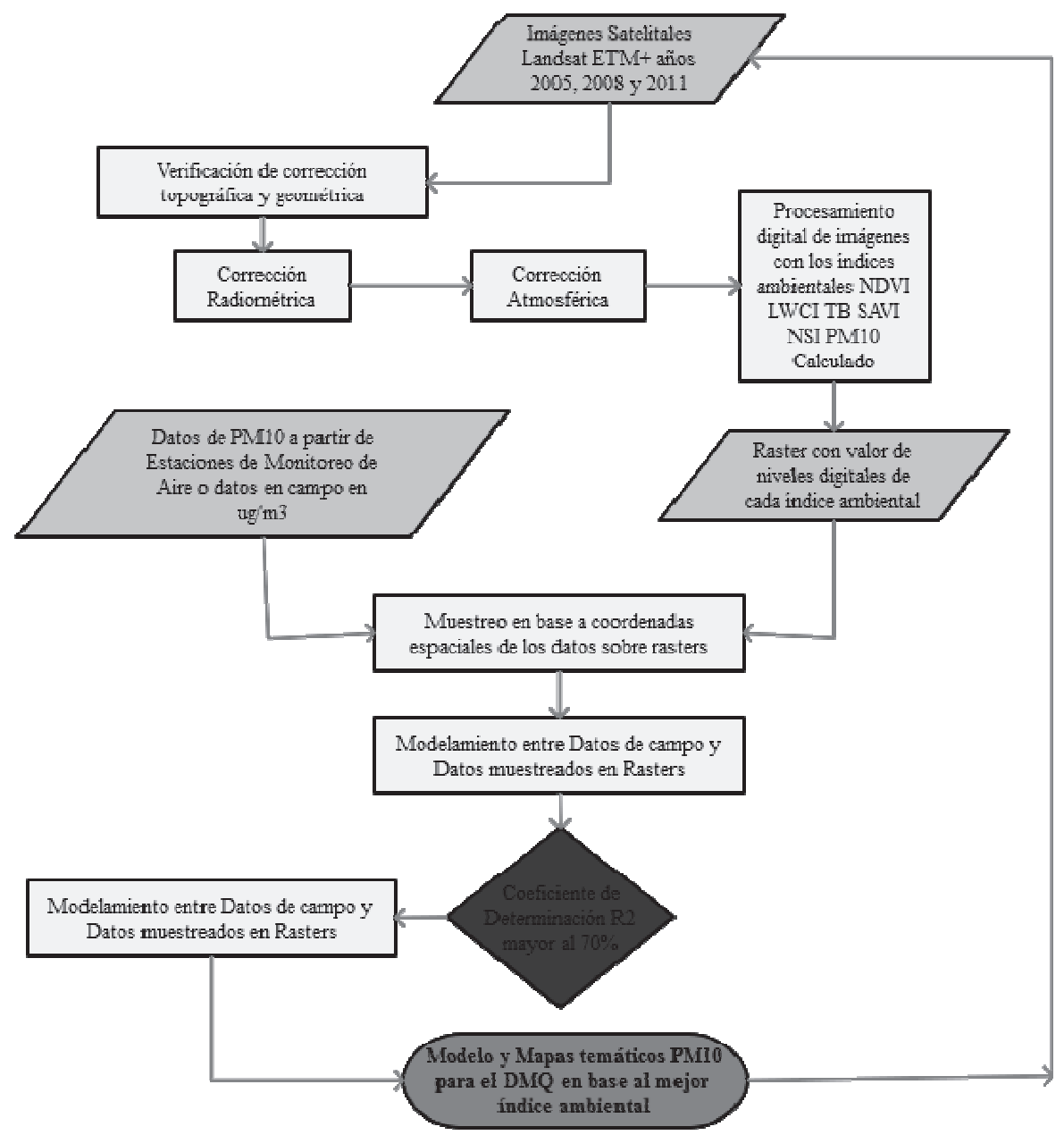

Figura 2. Esquema metodológico del proyecto.

\section{Modelación de datos}

Para realizar la modelación ya con los datos de las imágenes satelitales se realizaron las diferentes correcciones y cálculos de índices. Entre los datos modelados se seleccionaron los índices ambientales NDVI (Índice de vegetación de diferencia normalizado), LWCI (Índice de contenido de agua en hojas), T (Temperatura de Brillo), SAVI (Índice de vegetación ajustado al suelo), NSI (Índice de diferencia normalizada de suelos) y PM10 Calculado y los datos de PM10 tomados en campo por las estaciones de monitoreo pasivo para obtener modelos mediante regresiones. 
NDVI ha sido reconocido como uno de los indicadores más útiles para el estudio de características de la biosfera terrestre y su dinámica, a nivel global, regional y local (Chuvieco, 2002). El modelo se muestra en la Ecuación 1.

$$
N D V I=\frac{N I R-R}{N I R+R}
$$

Donde,

$\mathrm{NIR}=$ Infrarrojo Cercano Banda 4 en Landsat 7

$\mathrm{R}=$ Rojo Banda 3 en Landsat 7

LWCI se basa en la interrelación entre las reflectividades en el infrarrojo de onda corta (SWIR) y en el NIR. Fue obtenido aplicando la Ecuación 2.

$$
L W C I=\frac{-\log (1-(\text { NIR }-S W I R))}{-\log (1-(\text { NIRFT }-S W I R F T))}
$$

Donde,

$\mathrm{NIR}=$ Infrarrojo Cercano Banda 4 en Landsat 7

SWIR $=$ Infrarrojo de Onda Corta 1 Banda 5 en Landsat 7

NIRFT $=$ Valor máximo Infrarrojo Cercano Banda 4 en Landsat 7

SWIRFT $=$ Valor máximo Infrarrojo de Onda Corta 1 Banda 5 en Landsat 7

$\mathrm{T}$, se obtiene a partir de corregir radiométricamente y atmosféricamente las bandas térmicas del Landsat y la radiancia espectral a nivel de sensor, de la banda térmica, usando lo determinado en el libro del Proyecto Landsat (NASA, 2008) utilizada para la corrección atmosférica del térmico en la Ecuación 3.

$$
T=\frac{K 2}{\ln \left(\frac{K 1}{C A T}+1\right)}
$$

Donde, K1 y K2= Constantes de temperatura para el satélite Landsat 7 (666.09 y 1282.71 respectivamente).

$\mathrm{CAT}=$ Valores de Radiancia de la Banda térmica de Landsat 7.

SAVI es apropiado para regiones que tienen baja cubierta vegetal y consecuentemente alto porcentaje de reflectancia del suelo, aplicando la Ecuación 4.

$$
S A V I=\left[\frac{(N I R-R)}{(N I R+R+L)}\right](1+L)
$$


Donde,

NIR $=$ Infrarrojo Cercano Banda 4 en Landsat 7

$\mathrm{R}=$ Rojo Banda 3 en Landsat 7

$\mathrm{L}=$ Coeficiente de ajuste de la vegetación, equivalente a 0.5 , recomendado para densidades intermedias (Chuvieco, 2010).

NSI, destaca las áreas construidas y en suelo desnudo, dado a que estas superficies son más reflectivas en el SWIR que en el NIR. Se calcula mediante la Ecuación 5 .

$$
N S I=\frac{S W I R-N I R}{S W I R+N I R}
$$

Donde,

NIR $=$ Infrarrojo Cercano Banda 4 en Landsat 7

$\mathrm{SWIR}=$ Infrarrojo de Onda Corta 1 Banda 5 en Landsat 7

PM10 Calculado, se obtiene mediante algunos parámetros como correcciones radiométricas, valores de radiancia y reflectancia, es decir corrigiendo los números digitales radiométrica y atmosféricamente, valores de ganancia alta y baja de la banda térmica del sensor Landsat ETM+, entre otros, se ha logrado definir la siguiente ecuación para determinación de PM10 (Othman et al., 2010), representado en la ecuación 6.

$$
P M 10_{C}=e_{0} R_{a t m 1}+e_{1} R_{a t m 2}+e_{2} R_{a t m 3}
$$

Donde,

PM10 $=$ Concentración de partículas $($ PM10) calculado desde imágenes Landsat.

$\mathrm{R}_{\mathrm{atmi}}=$ reflectancia atmosférica, $\mathrm{i}=1$ y 3 son el número de bandas, es decir la reflectancia atmosférica para la banda 1, 2 y 3, obtenidos a partir de Ecuación 6. $\mathrm{e}_{\mathrm{j}}=$ coeficientes algorítmicos, $\mathrm{j}=0,1,2$, determinados empíricamente. Estos coefieficientes se logran al realizar una regresión lineal multivariable con el método de mínimos cuadrados entre los valores de reflectancia atmosférica y PM10 obtenido en campo.

Posteriormente al determinar los modelos en base a regresiones con cada uno de los índices y los datos de campo, se calcularon cada uno de los coeficientes de determinación $\mathrm{R}^{2}$, el cual indica el ajuste del modelo y se procedió a mapear clasificándolo en base a la normativa ecuatoriana del TULSMA (Texto Unificado de Legislación Medio Ambiental del Ministerio del Ambiente Ecuador) y a los valores de la OMS. 


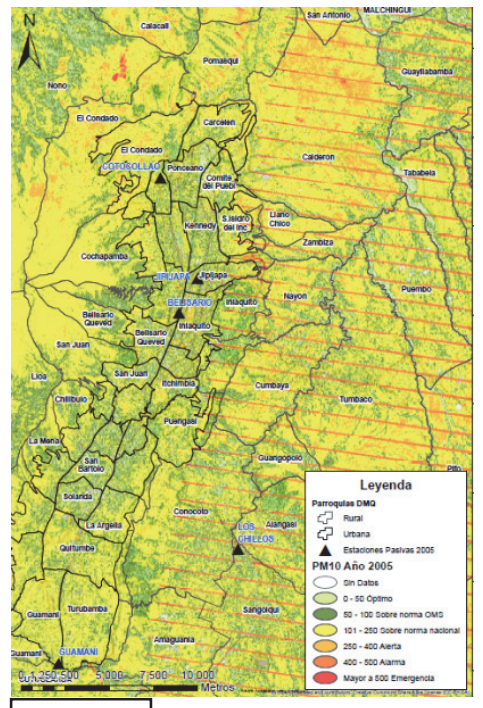

(a) 2005
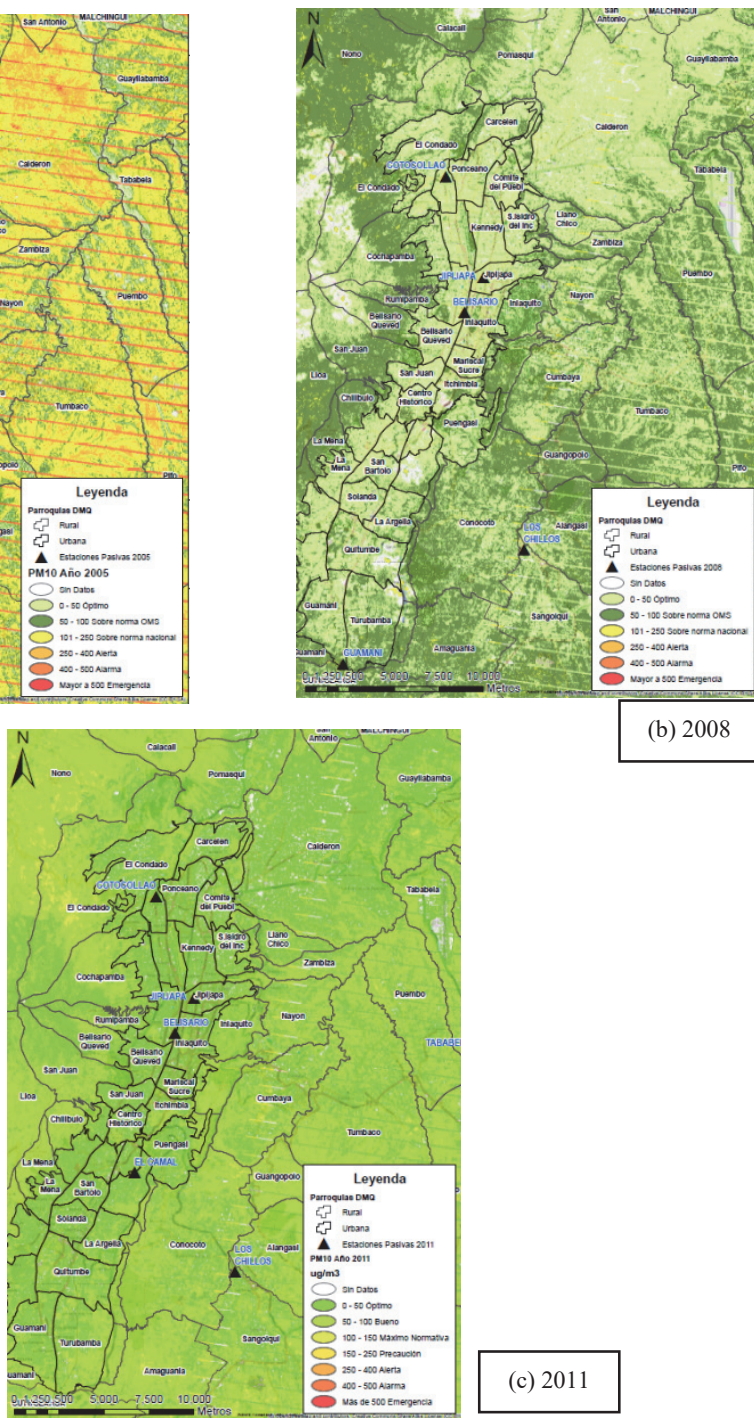

(b) 2008

\section{(c) 2011}

Figura 3. Mapeo de PM10, cálculo basado en el modelo de regresión lineal múltiple para cada año de estudio (a) 2005, (b) 2008, (c) 2011 con leyenda basada en normativa TULSMA en $\mu \mathrm{g} / \mathrm{m}^{3}$. 


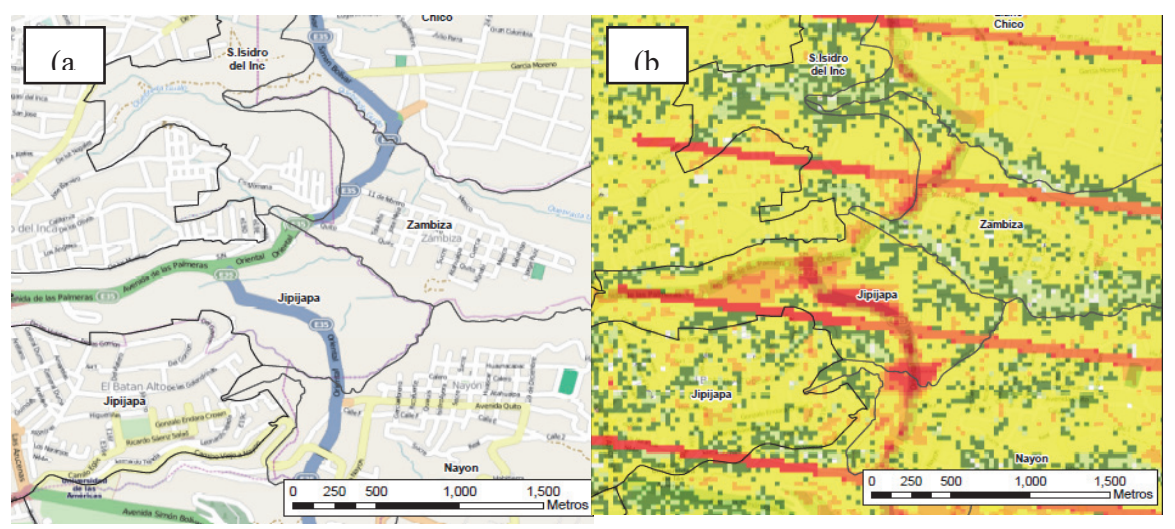

Figura 4. (a) Ubicación actual de zona de antiguo botadero de Zambiza cerrado en el año 2003 en el DMQ entre a la Avenida Simón Bolívar, Eloy Alfaro y De Las Palmeras. (b) Resultado de aplicación de modelo para el año 2005 en la zona de Zambiza, donde se puede observar la concentración en color Rojo más alta sobre la zona donde se ubicaba el botadero y se empezó a realizar la construcción de la prolongación de la Avenida Simon Bolivar. Las tres líneas paralelas en rojo son las zonas donde se identifica el problema de las imágenes Landsat 7 ETM+ SLC-off data (NASA, 2008).

\section{Resultados}

Los resultados de la investigación muestran que el modelo seleccionado obtuvo un coeficiente de determinación $\mathrm{R}^{2}$ mayor al $90 \%$ para cada uno de los años investigados (Tabla 2), así se puede definir que el modelo de PM10 Calculado en base a una regresión lineal múltiple donde sus variables independientes son las bandas 1, 2 y 3 del Landsat 7 con sus respectivas correcciones de radiancia y reflectancia y los coeficientes obtenidos a partir de la correlación con los valores promedios diarios de PM10 en $\mu \mathrm{g} / \mathrm{m}^{3}$ de las estaciones semiautomáticas, sirven para aplicación en ciudades de características similares a Quito en el Ecuador con buenos resultados.

Una vez definidos los modelos que se aplicarán para cada uno de los años en base al coeficiente de determinación $\mathrm{R}^{2}$ más alto (Tabla 3), se definió el modelo para todas las imágenes con su ecuación respectiva tanto para los años 2005, 2008 y 2011 (Figura 3), clasificándolos de manera espacial de acuerdo a la tabla del TULSMA Libro VI Anexo 4 del Ministerio del Ambiente para valores permisibles de PM10. Los polinomios sirven para cada año definido en base a los datos que se obtuvieron en ese tiempo respectivamente. 
Tabla 2

Coeficiente de determinación $\mathbf{R}^{2}$ para los dos modelos de regresión que mejor se ajustan para determinar PM10 a partir de índices ambientales

\begin{tabular}{cllc}
\hline \multicolumn{1}{c}{ Imagen } & \multicolumn{1}{c}{ Tipo de regresión } & \multicolumn{1}{c}{ Índice } & $R^{2}$ \\
\hline 09 de julio de 2005 & Polinómica de 2do. grado & SAVI & 0,726 \\
& Lineal múltiple & PM10 Calculado & 0,999 \\
17 de julio de 2008 & Polinómica de 2do. grado & NSI & 0,495 \\
& Lineal múltiple & PM10 Calculado & 0,942 \\
08 de junio de 2011 & Polinómica de 2do. grado & LWCI & 0,315 \\
& Lineal múltiple & PM10 Calculado & 0,983 \\
\hline
\end{tabular}

Tabla 3

Ecuaciones finales del modelo PM10 calculado que mejor se ajusta a cada año con las imágenes Landsat 7 definidas

\begin{tabular}{|c|c|c|}
\hline Imagen & Ecuación & $R^{2}$ \\
\hline 09 de julio de 2005 & $\mathrm{PM}_{10} 0_{2005}=462,927-10863,881 \mathrm{R}_{\mathrm{atm} 1}+789,300 \mathrm{R}_{\mathrm{atm} 2}+7046.990 \mathrm{R}_{\mathrm{atm} 3}$ & 0,999 \\
\hline 17 de julio de 2008 & PM10 ${ }_{2008}=0,669-27,283 R_{a t m 1}+1332,318 R_{a t m 2}-1023,902 R_{a t m 3}$ & 0,942 \\
\hline 08 de junio de 2011 & $\mathrm{PM} 0_{2011}=48,445-896,818 \mathrm{R}_{\mathrm{atm} 1}+2858,231 \mathrm{R}_{\mathrm{atm} 2}-2113,895 \mathrm{R}_{\mathrm{atm} 3}$ & 0,983 \\
\hline
\end{tabular}

Se puede puntualizar que existieron zonas identificadas claramente donde se puede identificar como el PM10 se ha concentrado en base a los modelos. Así sectores como San Antonio de Pichincha donde se conoce la presencia de canteras existen datos altos de PM10. De la misma manera el sector de Zambiza (Figura 4) donde se encontraba el antiguo botadero de basura de Quito es otro lugar identificado con concentraciones altas de PM10.

\section{Conclusiones}

El modelo que mejor se ajusta al cálculo de PM10 para Quito es justamente el llamado PM10 calculado basado en una regresión lineal múltiple para los tres años, donde la significancia de cada una de las 3 bandas que intervienen en la ecuación es importante para su determinación.

El PM10 afecta directamente a los valores de reflectancia de las imágenes satelitales, es así que se tienen valores de $\mathrm{R}^{2}$ superior al $90 \%$ en el momento de generar el modelo, considerándose así que donde existan problemas de contaminación de aire se podrá inferior y analizar estos con imágenes satelitales. 
A partir de imágenes satelitales se puede obtener valores de PM10 sin la necesidad de tener una gran cantidad de datos, así con esta información muchas ciudades en el país podrán aplicar el modelo solo basándose en realizar ciertas mediciones en diferentes puntos.

Los índices ambientales típicos como NDVI, LWCI, TB, SAVI y NSI pudieron ser calculados y determinados de manera correcta, pero para este modelo no tuvieron alta significancia en comparación al modelo de PM10 Calculado que involucra la relación lineal entre AOT y PM10 al momento de determinar el coeficiente de determinación $\mathrm{R}^{2}$, considerándose que estos índices deberían ser motivo de estudio constante para otras investigaciones.

Dentro de las zonas con mayor cambio en concentración por PM10 se pueden definir que se encontró lugares típicos donde es conocido la presencia de este contaminante como San Antonio de Pichincha con sus canteras, Tabacundo con las diferentes florícolas, Zambiza y el antiguo botadero de basura de la ciudad, entre otros para el año 2005. Para el caso del año 2008 y 2011 la concentración de PM10 en la ciudad se mantiene en niveles aceptables aún, cumpliéndose dentro de la normativa del TULSMA. No obstante esto se da en Quito, pero vale la pena realizar el estudio en otras ciudades donde no existen estudios o análisis de presencia de PM10 para conocer como es su comportamiento y determinar cómo aplicar una mejor Gestión Ambiental en el aire, adicional a estudios con otros contaminantes del aire e imágenes satelitales.

\section{Bibliografía}

Chuvieco, E. (2002). Teledetección ambiental, la observación de la tierra desde el espacio, Editorial Ariel Ciencia, Barcelona España.

Chuvieco, E. y Hantson, S. (2010). Procesamiento estándar de imágenes Landsat, Instituto Geográfico Nacional, 1(1). Disponible en: $<$ http://www.ign.es/PNT/pdf/especificaciones-tecnicas-pnt-mediar-landsat_v22010.pdf>

Ministerio del Ambiente (2012). Texto Unificado de Legislación Secundaria Medio Ambiental (TULSMA).

NASA (2008). Landsat 7 Handbook. Radiometric Characteristics [On line]. Disponible en: <http://landsathandbook.gsfc.nasa.gov/data_properties/>

Othman, N.; Mat, M. and Hwee, L. (2010). "Estimating Particulate Matter Concentration over Arid Region Using Satellite Remote Sensing: A Case Study in Makkah, Modern Applied Science, 4(11). Disponible en: $<$ http://www.ccsenet.org/journal/index.php/mas/article/download/6363/6063> 
Organización Mundial de la Salud (OMS) (2014). Calidad del aire (exterior) y Salud Nota Descriptiva No. 313. Disponible en: <http://www.who.int/ mediacentre/factsheets/fs313/es/>

Santana, L.; Escobar, L. y Capote, P. (2010). "Estimación de un índice de calidad ambiental urbano, a partir de imágenes de satélite", Revista de Geografía Norte Grande, núm. 45, pp. 77-95.

Secretaría del Ambiente de Quito (2014). Caracterización física y química del material particulado MP10. Disponible en: <https://sites.google.com/site/ redesmanualesypasivas/caracterizacion-quimica-y-fisica-de-material-particulado - pm10>

The Yale Center for Earth Observation (2010) Converting Landsat TM and ETM+ thermal bands to temperature. Disponible en: <http://www.yale.edu/ceo/ Documentation/Landsat_DN_to_Kelvin.pdf $>$ 